\title{
АНАЛИЗ И ЭКОНОМИЧЕСКАЯ ЦЕЛЕСООБРАЗНОСТЬ ПРИМЕНЕНИЯ ИННОВАЦИОННЫХ ДЕРЕВЯННЫХ ТЕХНОЛОГИЙ СТРОИТЕЛЬСТВА
}

\section{(c) 2019 Брыжатый Даниил Ринатович}

бакалавр, студент магистратуры кафедры строительных материалов и технологий строительства

Сибирский федеральный университет, Россия, Красноярск

E-mail: bruzhatui@yandex.ru

(C) 2019 Пронин Павел Викторович

студент кафедры радиосистем и комплексов управления

Сибирский федеральный университет, Россия, Красноярск

E-mail:g.f.05@inbox.ru

\section{(c) 2019 Можора Мария Алексеевна}

студентка кафедры психологии и консультирования

Сибирский федеральный университет, Россия, Красноярск

E-mail:m.mozhora@yandex.ru

\section{(c) 2019 Зайцева Анжелика Александровна}

студент кафедры промышленного и гражданского строительства

Сибирский федеральный университет, Россия, Красноярск

E-mail: anje.zaitseva@yandex.ru

\section{(c) 2019 Родионенко Евгения Викторовна}

студент кафедры промышленного и гражданского строительства

Сибирский федеральный университет, Россия, Красноярск

E-mail: rodionaaaa@mail.ru

\section{(c) 2019 Короткова Светлана Андреевна}

студент кафедры экспертизы и управления недвижимостью

Сибирский федеральный университет, Россия, Красноярск

E-mail: svetlanna4443@gmail.com

В России строительство зданий из дерева начинает приобретать новые обороты. Основной проблемой деревянного домостроения является усадка здания. Инновационные способы возведения деревянных зданий решают данную проблему. В данной работе рассмотрены современные технологии строительства деревянных домов, проанализированы их достоинства и недостатки, определена оптимальная инновационная технология для строительства деревянного дома в климатических условиях России.

Ключевые слова: древесина, технологии строительства, характеристики материала, преимущества, обработка.

\section{1. Введение}

Древесина - с экологической точки зрения - лучший строительный материал. Это органический материал, который сгорает при высокой температуре. Неверно изготовленные и незащищенные деревянные конструкции обладают недостаточной огнестойкостью, как следствие, загораются и распространяют пламя. Поэтому нужно уделять особое внимание обработке данного строительного материала и технологии строительства.
Древесина - своенравный и капризный материал, так как из-за пористости содержит влагу, количество которой меняется. Поэтому деревянные элементы могут коробиться и трескаться. Жесткость и твердость древесины не так высоки, как у металла, но соотношение плотности и прочности у древесины соответствует значениям металлических конструкций. Малая твердость древесины поперек волокон приводит к ее смятию в месте приложения нагрузки.

Весомая ценность древесины при строитель- 
стве это то, что её возможно склеить между собой или соединить гвоздями и саморезами. Сам материал хорошо поддается обработке и отделке. Несущие конструкции деревянного дома долговечны, обладают отличными звукоизоляционными свойствами, отличаются небольшим весом, и обеспечивают комфортный для человека температурно-влажностный режим. Древесина при правильном применении не загнивает и не разлагается. Деревянные конструкции обладают повышенной устойчивостью к осадкам фундамента и сейсмическим нагрузкам [1]. Применение деревянных изделий позволит уменьшить затраты ресурсов на возведение фундамента, так как удельный вес сухой древесины в три раза ниже, чем кирпичной кладки из силикатного кирпича. Следующее достоинство древесины её низкая теплопроводность (деревянная стена толщиной 45 см удерживает такое же количество тепла, как кирпичная стена толщиной 200 см), кроме того, деревянный дом требует на протопку меньше времени, чем кирпичный [2].

Одновременно с применением популярных методов возведения деревянных зданий появляются новые: технология Cross Laminated Timber, «Унипанель», технология Massiv-HolzMauer и Naturi.

Цель данной статьи - проанализировать и сравнить появившиеся методы возведения зданий из дерева и определить дальнейшие перспективы развития данных технологий.

Задачи данной статьи включают:

1. Анализ новых технологий строительства из древесины, их достоинств и недостатков.

2. Изучение опыта применения новых технологий и определение основных направлений развития.

3. Сравнение выбранных технологий по технико-экономическим показателям возводимого жилья и по эксплуатационным и физическим характеристикам.

\section{2. Методы}

В работе рассматриваются новые технологии строительства домов из древесины с помощью теоретического метода исследования (анализ и синтез). Проводится исследование достоинств и недостатков материала. В качестве значимых характеристик принимаются сроки возведения, пожарная опасность, наличие усадки, теплопроводность, сейсмическая устойчивость, скорость возведения дома с площадью $200 \mathrm{~m}^{2}$, стоимость $1 \mathrm{M}^{3}$ в России. В процессе работы формируется полная картина, характеризующая сильные и слабые стороны каждой из рассматриваемых технологий, благодаря чему исследование не только позволяет выявить среди существующих на сегодняшний день наиболее приемлемые варианты, но и определить направление развития каждой из технологий в сторону улучшения их характеристик.

На сегодняшний день известны 4 новейших технологий деревянного домостроения. Это - технология Cross Laminated Timber (перекрестно-клееная древесина), она же XLAM, технология Унипанель, технология MassivHolz-Mauer (массивная деревянная стена) и технология Naturi. Далее рассмотрим каждую в отдельности.

CLT метод возведения с применением многослойных деревянных клееных панелей.

CLT - Cross Laminated Timber (перекрестноклееная древесина), другими словами - многослойные деревянные панели. Данный материал применяется как для стеновых панелей, так и для балок несущих конструкций.

Данная панель состоит из нескольких последовательно склеенных между собой ламелей. У каждого последующего слоя направление волокон строго перпендикулярно. Для достижения максимальной прочности изделия, склеивание производится с чередованием направления деревянных волокон, это так же способствует исключению деформации в дальнейшем. Свойства панелей близки к железобетону, но являются более экологичными, так как при производстве используется натуральный клеевой состав.

Технология появилась в 90х и уже через 10 лет быстро набрала популярность на рынке, с помощью нее построили сотни домов в Европе, Австрии, Канаде и США. На сегодняшний день строят многоэтажные дома, с применением данной технологии. А если совмещать их с бетоном, то появляется возможность возведения зданий высотой более 10 этажей. Примером реализованных деревянных многоэтажных проектов являются «Brock Commons» в Канаде (18 этажей высотой 53 метра) и «Treet Bergen» в Норвегии (14 этажей высотой 51 метр) и пока нереализованных 42 этажный «Timber Tower Research Project», США и 40 этажный «Office Building of the Future».

B России CLT-панели начали производить в 2012 году. Данная технология начинает набирать популярность среди малоэтажного строитель- 
ства, но применение технологии CLT для многоэтажных зданий в России пока невозможно, так как нормативная база в нашей стране не допускает строительства многоэтажек из дерева.

В сравнении с классическими материалами для возведения зданий перекрестно клееные плиты обладают целым рядом преимуществ:

- Отсутствие усадки;

- Возможность выполнения уличной части стены любыми материалами, а так же возможность монтажа навесного фасада;

- Хорошая несущая способность - позволяет возводить дома высотой до 10 этажей без использования дополнительных материалов;

- Высокая устойчивость к открытому огню (скорость горения - 0,8 мм в минуту);

- Небольшой вес способствует использованию легкого фундамента;

- Высокий темп строительства, отделки здания, так как плиты изготовленные в заводских условиях не требуют впоследствии оштукатуривания;

- Устойчивость к горизонтальным силам выше, чем у бетонных зданий, что позволяет строить дома в сейсмических районах с силой толчков в 7-8 баллов почти без повреждений.

Недостатки CLT панелей:

- Крупный размер и значительный вес для монтажа CLT панелей требуют использования специализированного транспорта, вследствие этого увеличиваются затраты;

- Уменьшение размеров панели приводит к повышению стыковых соединений, это ведет к появлению потенциальных мостиков холода. Это усложняет конструкцию и увеличивает себестоимости сборки;

- Необходимость подъемной техники увеличенной мощности для монтажа, которая не всегда может проехать на стройплощадку;

- Низкая устойчивость древесины к ультрафиолетовому излучению требует обустройства вентилируемого фасада или покрытия специальными составами;

- Практика показывает, что нужно учитывать влияние влаги и исключать ее путем сжатия элементов или исключением доступа влаги.

\section{Massiv-Holz-Mauer (MHM)}

Massiv-Holz-Mauer (MHM) - это технология с использованием готовых комплектов, которая позволяет быстро возводить здания. Технология подразумевает использование щитов из хвойных пород дерева. В будущей конструкции, во время обработки на заводе, выпиливают необходимые проемы, пазы под электропроводку и трубопровод, а также отверстия для вентиляционной системы и на выходе получается готовый элемент дома, который остается только установить на место. Производство осуществляется исключительно из неделовой древесины 3-4 сортов, доводя готовую конструкцию до влажности не более $14 \%$. Отличие от CLT панелей заключается в том, что панели не склеиваются между собой, а соединяются алюминиевыми штифтами.

Производство панелей началось в 2001 году в Германии, а в России - только в 2007. Наиболее известными зданиями, построенными по технологии MНМ являются: отель Waldeck Spa Kur в Бад-Дюхрайме, дом престарелых в Вайссенхорне и католическая церковь в Рёне.

По заявлению специалистов швейцарской компании Struby Holzbau AG, конструкции MHM защищены от воздействия грибка и плесени. Благодаря термообработке происходит запекание смолы, которая действует как защитный слой и не требует обработки материала антисептиками, но возникает потребность в защите от негативных воздействий.

После согласования проекта с заказчиком, щиты изготавливают на заводе. На создание комплекта для дома уходит от 1 до 3 дней. После этого готовые части дома поступают на объект и собираются при помощи крана.

Достоинства и недостатки технологии МНМ:

- Возможность строительства коттеджа «под ключ» за 2-4 месяца, что немаловажно для северных регионов страны;

- Отсутствие усадки;

- Экологичность;

- Шумоизоляция - до 48 дБ (в зависимости от толщины полотна);

- Классы пожарной безопасности - К1(45), K0(4), K0(15);

- Теплопроводность - 0,093 Вт/м* С;

- Средний срок эксплуатации - 150 лет;

- Уровень теплоизоляции щитов МНМ и кирпичной кладки: 34.5 см $=100$ см;

- Отражают примерно 97,5\% высокочастотного электромагнитного излучения;

Практическое применение МНМ-панелей выявило ряд недостатков, таких как:

- Большой расход дерева и обязательное наличие крана на площадке;

- Качество досок и наличие горбыля в средних слоях панели; 
- Плохая морозостойкость самого материала;

- Отсутствие антисептической и противопожарной обработки, в некоторых случаях, сказывается на качестве материала.

\section{Технология Naturi}

Технология «Naturi» - это инновационный метод возведения деревянных домов. Отличие данной технологии заключается в вертикальном расположении брусьев вместо горизонтально уложенных венцов. Преимущество «Naturi» состоит в отсутствии усадки здания во время эксплуатации.

Как говорят эксперты, вертикальная установка брусьев практиковалась еще в древней Руси. Усадьба в Мураново, построенная в 1841 году, является подтверждением этой гипотезы. Возрождение способа началось в Австрии, дома, возведенные из вертикальных брусьев, хорошо проявили себя в суровых климатических условиях. Данная технология подходит для строительства энергоэффективного дома из дерева, а также исключает проблемы усадки и деформаций.

Преимущества технологии «Naturi»:

- Ограждающие конструкции имеют огромную прочность и собираются как конструктор благодаря сложному поперечному сечению бруса. Профилированные бревна скрепляются в паз-гребень и с помощью нагелей. Возможно собрать стенки любой толщины и формы. Так же конструкция не требует дополнительной отделки и утепления.

- Экологичный материал подразумевает, что выделение каких-либо веществ после обработки или склеивания, не будет превышать определенных значений. Данная конструкция является самой экологичной, так как при её производстве не используются клеи и пропитки.

- Микрозазоры в конструкции позволяют дому «дышать», и в тоже время, за счет сложной структуры сечения, стены полностью сдерживают ветровые потоки.

Будущий профилированный брус высушивается до небольшого процента влаги, после пропускания через матрицы заворачивается в специальную термоизоляционную пленку до поступления на стройплощадку. После сборки дерево немного набирает влагу из воздуха и, разбухая, брусья прочно сцепляются друг с другом так, что дальнейший демонтаж невозможен.

Так же для достижения лучшего результата при производстве необходимо использовать разные сорта древесины: для наружного слоя лиственницу, которая не гниет и не пропустит влагу, а для внутреннего - кедр, который создает комфортные условия для нахождения внутри здания.

Из-за сложной системы соединения брусьев для их изготовления необходимо применять высокоточное токарно-фрезерное оборудование. Для возведения дома необходимо привлекать высококвалифицированных специалистов, которые имеют опыт сборки. Все детали будущего дома проходят через систему компьютерного моделирования, так как самое небольшое отклонение от проекта может привести к накоплению погрешностей, а один неровно уложенный или кривой брусок способен испортить всю стену.

\section{Технология «Унипанель»}

Унипанель (инженерная древесина) - еще одна из инноваций, отличающаяся от других технологий возможностью использования в качестве отделочного материала или несущей конструкции. Волокна расположены вдоль решетчатой структуры панели - каждый слой имеет продольные запилы с двух сторон на всю длину и склеивается слоями под прямым углом. По требованию заказчика внешние слои конструкции могут быть выполнены из других материалов таких, как шпон, древесноволокнистной плиты, пластика и других. Максимально возможные размеры панелей $1200 \times 330$ см при толщине 3-50 см.[3]

УНИПАНЕЛЬ - восемь механизмов устойчивости:

- Многослойность - перекрестное склеивание.

- Незначительное перерезание волокон.

- Минимальная зона клеевого контакта стержневых элементов.

- Малое сечение стержневых элементов.

- Радиальные и тангенциальные влажностные деформации древесины стержневых элементов происходят в пределах дилатационных зазоров и не влияют на два главных размера строительного элемента.

- Дезинтеграция влияния местных пороков древесины.

- Диффузия паров в воздушном слое дилатационных пазов на порядок выше, чем в массиве древесины, следовательно, влажность в объеме строительного элемента выравнивается намного быстрее и при минимальных напряжениях [3]. 
Достоинства технологии «Унипанель»:

- Как показывает практическое применение, такое уникальное решение позволяет забыть об любых деформациях и производить отделку сразу после возведения конструкции. Реверсивность конструкции позволяет ее эксплуатировать даже после замачивании выше предела гигроскопичности. Эта характеристика исключает необходимость использования пароизоляционную пленку;

- Эксплуатация конструкции возможна при любых температурно-влажностных режимах;

- Преимущество клееной хвойной породы в конструкции хороший показатель теплопроводности в 1,5 раза теплее массива сосны или ели, такой же толщины. При желании, можно добиться обхода без дополнительного утепления;

- Для создания «унипанелей» в основном используется невысокосортная древесина, но достигается максимальный жизненный цикл как у клееной древесины;

- Устойчивость к сейсмическим нагрузкам до 8 баллов;

- Содержание клея менее 2\% (у ДСП от 11\%);

- За счет вырезов намного легче на 40-60\%, чем массив сосны или ели;

- Инвариантность финишной отделки: материал может изготавливаться без отделки и с заводской отделкой.

Недостатки:

- Отсутствие биозащиты.

\section{3. Результаты и обсуждение}

По итогам исследования составим сравнительную таблицу характеристик рассмотренных технологий (см. табл. 1).

\section{Заключение}

Все современные технологии строительства деревянных домов показывают отличное сопротивление усадке здания в период эксплуатации, так как создание их было направлено на решение данной проблемы. Что касается теплопроводности, то лучшие показатели у технологии «Унипанель», на втором месте МНМ, это значит, что для сурового климата нашей страны отлично подойдут эти методы. Все представленные технологии хорошо сопротивляются огню, кроме «Naturi», так как данный метод не предусматривает обработку антипиренами для огнезащиты. Технология Massiv-Holz-Mauer оказалась самой быстровозводимой и самой дешевой. Все здания, построенные по представленным технологиям готовы справиться с горизонтальными нагрузками в виде сейсмических воздействий. Срок эксплуатации у всех конструкций примерно одинаков.

Анализируя все вышесказанное можно сделать вывод, что технология строительства деревянных домов Massiv-Holz-Mauer самая оптимальная по технико-экономическим, физическим и эксплуатационным характеристикам для России.

Таблица 1. Характеристики технологий деревянного домостроения

\begin{tabular}{|c|c|c|c|c|}
\hline Характеристика & $\begin{array}{l}\text { Cross Laminated } \\
\text { Timber }\end{array}$ & Massiv-Holz-Mauer & Naturi & Унипанель \\
\hline $\begin{array}{l}\text { Срок эксплуатации } \\
\text { (без применения } \\
\text { дополнительных } \\
\text { средств) }\end{array}$ & 50 лет & 30 лет & 50 лет & 30-40 лет \\
\hline Пожарная опасность & $\begin{array}{l}\text { класс пожарной } \\
\text { безопасности: K1; }\end{array}$ & $\begin{array}{c}\text { класс пожарной } \\
\text { безопасности: К1; }\end{array}$ & $\begin{array}{c}\text { Информации нет, } \\
\text { но учитывая то, что } \\
\text { конструкция не об- } \\
\text { рабатывается анти- } \\
\text { пиретами, показате- } \\
\text { ли по огнестойкости } \\
\text { будут низкими }\end{array}$ & $\begin{array}{l}\text { класс пожарной } \\
\text { безопасности: К1; }\end{array}$ \\
\hline Наличие усадки & нет & нет & нет & нет \\
\hline $\begin{array}{l}\text { Теплопроводность } \\
\text { вт/м* C }\end{array}$ & $0,1-0,14$ & 0,093 & 0,3 толщиной & 0,087 \\
\hline $\begin{array}{l}\text { Сейсмическая } \\
\text { устойчивость }\end{array}$ & $\begin{array}{c}\text { До } 8 \text { баллов } \\
\text { по шкале Рихтера }\end{array}$ & $\begin{array}{c}\text { До } 8 \text { баллов } \\
\text { по шкале Рихтера }\end{array}$ & $\begin{array}{c}\text { До 7-8 баллов } \\
\text { по шкале Рихтера }\end{array}$ & $\begin{array}{c}\text { До } 8 \text { баллов } \\
\text { по шкале Рихтера }\end{array}$ \\
\hline $\begin{array}{l}\text { Сроки монтажа } \\
\text { дома площадью } \\
200 \mathrm{~m}^{2}\end{array}$ & От 6 до 9 дней & от 4 до 7 дней & $\begin{array}{c}\text { собирается за 20-30 } \\
\text { дней }\end{array}$ & около 20 дней \\
\hline $\begin{array}{l}\text { Стоимость в России } \\
\text { за } 1 \mathrm{~m}^{3}\end{array}$ & 46000 руб. & 21070 руб. & 35000 руб. & 29000 руб. \\
\hline
\end{tabular}




\section{Библиографический список}

1. Ковальчук, Л.М. Основные направления совершенствования деревянных конструкций и повышения эффективности их применения в строительстве / Л.М. Ковальчук // Состояние и перспективы исследования в области деревянных строительных конструкций.- М.: ЦНИИСК им. В.А. Кучеренко, 1983.- С. 4-10.

2. СРАВНИТЕЛЬНЫЙ АНАЛИЗ ТЕХНОЛОГИЙ ДЕРЕВЯННОГО СТРОИТЕЛЬСТВА ЖаДаНОВ В.И., д-р техн. наук, профессор, Юкова К.В., Марсакова Е.В., Инжутов И.С., д-р техн. наук, профессор, Котлов В.Г. Оренбургский государственный университет Инженерно-строительный институт Сибирского федерального университета (г. Красноярск) Поволжский государственный технологический университет (г. Йошкар-Ола)

3. Инженерная древесина унипанель- [Электронный ресурс] - Режим доступа - URL: https://alldoma.ru/pressrelizy/inzheneraya-drevesina-unipanel.html

4. Конструктивная система Naturi в ряду технологий деревянного домостроения- [Электронный ресурс] - Режим доступа - URL: https://naturi.su/news/konstruktivnaya-sistema-naturi-v-ryadu-tekhno

5. Технология производства моналитных стен по германской технологии Massiv-Holz-Mauer- [Электронный ресурс] - Режим доступа - URL: http://centrstroj.ulcraft.com/tiekhnologhiia_massivholzmauer 